\title{
CORRESPONDENCE
}

We welcome letters to the Editor concerning articles which have recently been published. Such letters will be subject to the usual stages of selection and editing; where appropriate the authors of the original article will be offered the opportunity to reply.

Letters should normally be under 500 words in length, double-spaced throughout, signed by all authors and fully referenced. The edited version will be returned for approval before publication.

\section{INCIDENCE OF CANCER AFTER TOTAL HIP REPLACEMENT}

\section{Sir,}

Correction: 'The incidence of cancer following total hip replacement' (J Bone Joint Surg [Br] 1988;70-B:539-42)

We have identified an error in the last paragraph of the discussion section of this article and wish to draw it to the attention of your readers. The second sentence of the last paragraph should read "The risk of developing a lymphoreticular neoplasm remains small, increasing from 8.67 per 1000 over 10 years to 14.62 per 1000 in the same period on the operated group". These figures are the correct estimate derived from the data presented in the paper.

W. J. GILLESPIE, ChM, FRCS Ed, FRACS

Princess Margaret Rose Orthopaedic Hospital

Edinburgh, UK.

P. DOORN, PhD

Joint Replacement Institute

Los Angeles, USA.

Gillespie WJ, Frampton CMA, Henderson RJ, Ryan PM. The incidence of cancer following total hip replacement. J Bone Joint Surg $[\mathrm{Br}]$ 1988;70-B:539-42.

\section{CONSERVATIVE TREATMENT OF COMPLETE ACL TEARS}

Sir,

In their paper in the November 1995 issue entitled 'The conservative treatment of complete tears of the anterior cruciate ligament in skeletally immature patients' (1995;77-B: 890-4) Mizuta et al did not describe in detail the conservative rehabilitation programme which was central to their study. The few facts which were given show their conservative treatment to be somewhat outdated.

They do not mention the proprioceptive aspect which in the mature patient is an important part of any conservative treatment of the anterior-cruciate-ligament-deficient (ACLD) knee (Lephart

(C)1996 British Editorial Society of Bone and Joint Surgery

0301-620X/96/41258 \$2.00

J Bone Joint Surg [Br] 1996;78-B:680-4. and Fu 1995). Also, Beard et al (1994) have shown that it is the speed at which the hamstrings function rather than their strength which is important in the rehabilitation of the ACLD knee. A properly conducted rehabilitation programme on these lines may not have altered the results of the study, but their patients have not had the benefit of full conservative treatment designed to prevent "instability and progressive deterioration of the knee".

It is therefore difficult to accept their conclusion that the results of non-operative treatment for ACL injuries in this age group are “poor'.

M. J. CALLAGHAN, MPhil, Grad Dip Phys, MCSP

Royal Liverpool and Broadgreen University Hospitals NHS Trust Liverpool, UK.

Beard DJ, Dodd CAF, Trundle HR, Simpson AHRW. Proprioception enhancement for anterior cruciate ligament deficiency. J Bone Joint Surg [Br] 1994;76-B:654-9.

Lephart SM, Fu FH. The role of proprioception in the treatment of sports injuries. Sports Science and Injury 1995;1:96-102.

Mizuta H, Kubota K, Shiraishi M, et al. The conservative treatment of complete tears of the anterior cruciate ligament in skeletally immature patients. J Bone Joint Surg [Br] 1995;77-B:890-4.

\section{Author's reply:}

Sir,

We thank Mr Callaghan for his interest in our article. Our patients were treated between 1985 and 1990 and therefore their rehabilitation was not that which we would now use. We encouraged isometric quadriceps and hamstring exercises immediately after arthroscopy. As symptoms diminished, isotonic and isokinetic regimes were started. Half-squat, calf-raise, and step-up exercises and stationary bicycling were begun when the patient was comfortable. After the patients had regained about $80 \%$ of thighmuscle strength, a full range of movement and freedom from pain and swelling were gradually introduced with sport-specific rehabilitation under the supervision of a physician or a physiotherapist directed by a physician. Wearing a functional knee brace, the patients were given a programme of exercises including straight running, figure-of-eight running and jumping on both legs. A graduated return to sport was allowed when these exercises had been satisfactorily completed and the thigh-muscle strength had reached $90 \%$.

Although our rehabilitation programme may have had some favourable effects on the proprioceptive function of the injured knees, no special proprioceptive exercises were carried out. We do not know therefore whether the management advocated by Beard et al (1994) emphasising proprioceptive enhancement would have altered the results of our study. We are also interested in the neuromuscular control of dynamic knee stability through proprioceptive feedback in ACL-deficient knees, and we expect that future studies will show the efficacy of proprioceptive enhancement training for ACL-deficient knees in skeletally immature patients.

H. MIZUTA, MD

Kumamoto University School of Medicine

Kumamoto, Japan. 
Beard DJ, Dodd CAF, Trundle HR, Simpson AHRW. Proprioception enhancement for anterior cruciate ligament deficiency. J Bone Joint Surg [Br] 1994;76-B:654-9.

Sir,

I read with interest the article by Mizuta et al in the November 1995 issue entitled 'The conservative treatment of complete tears of the anterior cruciate ligament in skeletally immature patients' (1995;77-B:890-4). The authors present the results of the conservative management of complete mid-substance tears of the anterior cruciate ligament, confirmed at arthroscopy in 18 patients aged from 10 to 15 years, 16 of whom were girls. They give no information on the assessment of skeletal maturity by either radiological or physiological parameters such as Tanner staging or the menarche. It is wrong to assume, especially in girls, that there is skeletal immaturity in the age range studied.

The authors have demonstrated the natural history of untreated tears of the ACL. Despite the fact that their patients underwent a rehabilitation programme to re-establish a normal quadriceps and hamstring ratio, they did not follow the primary requirement of the conservative management of these injuries, namely the avoidance of high-level acceleration/deceleration sports which require a rapid change of direction. A significant number of them attempted to return to sport, but were unable to continue and it is therefore not surprising that they developed symptomatic knees. The wellknown sequelae of meniscal and articular injury became manifest.

I hope that this paper is not considered to be a guideline for ACL reconstruction in this age group. In patients with meniscal injuries which are repaired, concomitant injuries of the ACL should be reconstructed at the same time to protect the patient from progressive meniscal injury secondary to symptomatic cruciate instability.

Since the authors discuss the treatment of 'skeletally immature' patients, this requires documentation by radiological and/or physiological means, otherwise it cannot be assumed that the patients were truly skeletally immature.

C. L. STANITSKI, MD

Children's Hospital of Michigan

Detroit, USA.

Mizuta H, Kubota K, Shiraishi M, et al. The conservative treatment of complete tears of the anterior cruciate ligament in skeletally immature patients. J Bone Joint Surg [Br] 1995;77-B:890-4.

\section{Author's reply:}

Sir,

We thank Dr Stanitski for his interest in our article. In this study we defined 'skeletal immaturity' as the presence of open physes on radiographs of the involved knee. Radiological assessment of bone age and physiological evaluation, such as by the Tanner scoring method, were not used. The remaining potential for growth differed with each patient and we agree that the study may have lacked a strict assessment of skeletal maturity.

We recognise the necessity and importance of modification of activity in the conservative management of ACL tears. After confirmation of the injury, the patients and their parents were informed of the significance of the injury, including the predicted functional disability with progressive deterioration of the knee if recurrent episodes of instability occurred. They were counselled concerning activities which would place the knee at risk of further injury and were advised to avoid high-risk activities although the ultimate decision on a return to organised sport was left to them.
If our patients had complied more strictly with the advice to modify their activities, the results would probably have been better. In practice, however, it is difficult to modify activity in children, and the observation that 13 of our 18 patients had recurrent giving way in daily life, indicates this.

H. MIZUTA, MD

Kumamoto University School of Medicine

Kumamoto, Japan.

\section{QUANTIFYING OSTEONECROSIS OF THE FEMORAL HEAD USING MRI}

Sir,

We read with interest the reports of Koo et al in the November 1995 issue entitled 'Preventing collapse in early osteonecrosis of the femoral head' (1995;77-B:870-4) and 'Quantifying the extent of osteonecrosis of the femoral head' (1995;77-B:875-80). They clearly show that the probability of further collapse in osteonecrosis $(\mathrm{ON})$ of the head of the femur is not influenced by core decompression but is strongly correlated with the extent of the necrotic area within the head. Our investigations have produced a similar conclusion (Lafforgue et al 1993).

Studies on core decompression carried out only on the basis of radiological staging have provided conflicting results about the ability of this procedure to prevent collapse of the femoral head. MRI has shown evidence that good results from core decompression occur mainly when there is a small amount of necrosis, which may have a favourable outcome without treatment. In our experience $35 \%$ of such patients have a satisfactory result. The extent and the location of $\mathrm{ON}$ are the main determining factors in the outcome of early-stage $\mathrm{ON}$, with or without core decompression and MRI is the most accurate in assessing these parameters (Beltran et al 1990; Lafforgue et al 1993; Takatori et al 1993; Shimizu et al 1994; Holman et al 1995; Koo and Kim 1995; Steinberg, Hayken and Steinberg 1995). The definition of an international standardised method of ON quantification with MRI is now a priority.

P. LAFFORGUE, MD, PhD

C. CHAGNAUD, MD

P. C. ACQUAVIVA, MD

CHU La Timone

France.

J. N. ARGENSON, MD

J. M. AUBANIAC, MD

Hôpital Sainte-Marguerite

Sainte-Marguerite

France.

Beltran J, Knight CT, Zuelzer WA, et al. Core decompression for avascular necrosis of the femoral head: correlation between long-term results and preoperative MR staging. Radiology 1990;175:533-6.

Holman AJ, Gardner GC, Richardson ML, Simkin PA. Quantitative magnetic resonance imaging predicts clinical outcome of core decompression for osteonecrosis of the femoral head. J Rheumatol 1995; 22:1929-33.

Koo K-H, Kim R, Ko G-H, et al. Preventing collapse in early osteonecrosis of the femoral head: a randomised clinical trial of core depression. J Bone Joint Surg [Br] 1995;77-B:870-4.

Koo K-H, Kim R. Quantifying the extent of osteonecrosis of the femoral head: a new method using MRI. J Bone Joint Surg [Br] 1995; 77-B:875-80

Lafforgue P, Dahan E, Chagnaud C, et al. Early-stage avascular necrosis of the femoral head: MR imaging for prognosis in 31 cases with at least 2 years of follow-up. Radiology 1993;187:199-204.

Shimizu K, Moriya H, Akita T, Sakamoto M, Suguro T. Prediction of collapse with magnetic resonance imaging of avascular necrosis of the femoral head. J Bone Joint Surg [Am] 1994;76-A:215-23. 
Steinberg ME, Hayken GD, Steinberg DR. A quantitative system for staging avascular necrosis. J Bone Joint Surg [Br] 1995;77-B:34-41.

Takatori Y, Kokubo T, Ninomiya S, et al. Avascular necrosis of the femoral head: natural history and magnetic resonance imaging. $J$ Bone Joint Surg [Br] 1993;75-B:217-21.

\section{Author's reply:}

\section{Sir,}

I thank Dr Lafforgue and his colleagues for their valuable discussion of our papers and for their agreement with our findings. I agree with their interpretation of our study and also in their plea for standardising the assessment of osteonecrosis as seen on MRI. In the last few years an international task force at ARCO (Association Research Circulation Osseous, Service de Rheumatologie, University Hospital of Rangueil, F-31054 Toulouse Cedex, France) has been comparing the various studies. Active participation among interested researchers is strongly recommended.

K.-H. KOO, MD, PhD

Gyeong-Sang National University Hospital

Chinju, Republic of Korea.

\section{RSA IN THE ASSESSMENT OF ASEPTIC LOOSENING}

Sir,

I read with interest the editorial in the January 1996 issue entitled 'RSA in the assessment of aseptic loosening' by Nilsson and Kärrholm (1996; 78-B:1-3).

While agreeing in general terms that excessive amounts of subsidence will tend to be associated with loosening of the femoral implant, the precise amount is surely dependent on the design of the prosthesis.

The Exeter prosthetic stem is designed to allow taper engagement under load, and $2 \mathrm{~mm}$ of subsidence at the stem-cement interface would be much less significant, compared with, for example, that in a cemented 'precoat' femoral prosthesis, which is not meant to move at all within the cement.

J. R. LOUDON, FRCS

Wrightington Hospital for Joint Disease

Wigan, UK.

Nilsson KG, Kärrholm J. Editorial: RSA in the assessment of aseptic loosening. J Bone Joint Surg [Br] 1996;78-B:1-3.

\section{Authors' reply:}

Sir,

In our editorial we indicated that subsidence of a polished femoral component inside the cement mantle could be a 'normal' phenomenon. The Exeter stem, when used with a polished surface, will do well up to seven years after implantation (Herberts and Malchau 1996), but the significance of the subsidence of these components is not known. According to Verdenshot and Huiskes (1995) and Davies, Anderson and Harris (1996) subsidence of a polished stem inside the cement mantle exceeding $1 \mathrm{~mm}$ cannot be explained by creep alone, but indicates fracture of the cement. In the old and less active patient with a well-centralised stem in a homogeneous cement mantle which penetrates the trabecular bone as far as the inner surface of the cortex, and with a limited amount of particulate debris circulating in the periprosthetic space, the leakage of joint fluid through these fracture lines may be sufficiently small to allow a good clinical result.

Even grit-blasted femoral stems subside inside the cement mantle (Thanner et al 1995). The poor results of the matt Exeter design can probably be related to the generation of particles secondary to this movement. From a theoretical standpoint we think that an intact cement mantle is preferable even when a polished stem is used. Debonding of the stem and fracture of the cement may be unavoidable with current cementing techniques but the incidence will depend on the design of the stem, the quality of the cementing and the surgical technique. Further study of these features is required.

\section{K. G. NILSSON, MD, PhD \\ University Hospital \\ Umeå, Sweden. \\ J. KÄRRHOLM, MD, $\mathrm{PhD}$ \\ Sahlgren Hospital \\ Gothenburg, Sweden.}

Davies J, Anderson MJ, Harris WH. The cement-metal interface of the Exeter stem during fatigue loading of a simulated THA in situ. Trans Orthop Res Soc 1996;21:525.

Herberts P, Malchau H. Prognosis of total hip replacement. Surgical and cementing technique in THR: a revision risk study of 134,056 primary operations. Scientific Exhibition, AAOS 63rd Annual Meeting, Atlanta, 1996.

Thanner J, Freij-Larsson C, Kärrholm J, Malchau H, Wesslén B. Evaluation of Boneloc: chemical and mechanical properties, and a randomized clinical study of 30 total hip arthroplasties. Acta Orthop Scand 1995;66:207-14.

Verdenshot N, Huiskes R. The effect of bone-cement creep on the mechanical endurance of femoral total hip reconstructions. In: Verdenshot N. Biomechanical failure scenarios for cemented total hip replacements. Thesis. Den Haag: CIP-Gegevens Koninklijke Bibliotheek, 1995:85-102.

\section{EOSINOPHILIC SYNOVITIS}

Sir,

I refer to the article in the July 1995 issue entitled 'Eosinophilic synovitis: a new entity?' by Tauro (1995;77-B:654-6).

Eosinophilic synovitis is not a new condition since there have been several previous reports on synovial fluid eosinophilia and eosinophilic infiltration of the synovium after arthrography (Hasselbacher and Schumacher 1978), in metastatic carcinoma of the synovium (Goldenberg, Kelley and Gibbons 1975), in guineaworm joint infestation (Reddy, Parvathi and Sivaramappa 1969), after irradiation (Hasselbacher and Schumacher 1977), in atopy (Al-Dabbagh and Al-Irhayim 1983), in hypereosinophilic syndrome (Brogadir, Goldwein and Schumacher 1980), and in HLA B27-related arthropathy (Bissonnette and Beaudet 1983).

Dr Tauro's report adds another description in which the condition may be parasitic-related. It is important, however, that 'eosinophilic synovitis' should not be regarded as a specific condition, but as a descriptive term to describe an enigmatic synovial pathology which may be encountered in diverse clinical circumstances.

B. VERNON-ROBERTS, MD, PhD, FRCPath, FRCPA

University of Adelaide

Adelaide, South Australia.

Al-Dabbagh AI, Al-Irhayim B. Eosinophilic transient synovitis. Ann Rheum Dis 1983;42:462-5.

Bissonnette B, Beaudet F. Reactive arthritis with eosinophilic synovial infiltration. Ann Rheum Dis 1983;42:466-8.

Brogadir SP, Goldwein MI, Schumacher HR. A hypereosinophilic syndrome mimicking rheumatoid arthritis. Am J Med 1980;69: 799-802. 
Goldenberg DL, Kelley WL, Gibbons RB. Metastatic adenocarcinoma of synovium presenting as an acute arthritis. Arthr Rheum 1975; 18:107-10.

Hasselbacher P, Schumacher HR. Bilateral protrusio acetabuli following pelvic irradiation. J Rheumatol 1977;4:189-96.

Hasselbacher P, Schumacher HR. Synovial fluid eosinophilia following arthrography. J Rheumatol 1978;5:173-6.

Reddy CR, Parvathi G, Sivaramappa M. Adhesion of white blood cells to guinea worm larvae. Am J Trop Med Hyg 1969;18:378-81.

Tauro B. Eosinophilic synovitis: a new entity? J Bone Joint Surg [Br] 1995; 77-B:654-6.

\section{Author's reply:}

Sir,

I thank Professor Vernon-Roberts for drawing my attention to other conditions in which eosinophils are present in synovial fluid. They are, however, all isolated case reports with a known aetiological factor operating locally and not strictly comparable with the group of patients which I described.

B. TAURO, DOrth, MS Orth, MCh Orth

24 IRH Residential Complex

Greenock, UK.

\section{ACUTE COMPARTMENT SYNDROME IN TIBIAL DIAPHYSEAL FRACTURES}

\section{Sir,}

The paper in the January 1996 issue entitled 'Acute compartment syndrome in tibial diaphyseal fractures' by McQueen, Christie and Court-Brown (1996;78-B:95-8) is valuable in so far as it stimulates further debate on an important subject, but the authors' conclusion that "Our results show that the use of early continuous compartment monitoring significantly reduced the delay to fasciotomy ..." is not supported by the data.

Retrospectively, the protocol allowed the institution of pressure monitoring "at the discretion of the surgeon in charge", and the diagnosis of acute compartment syndrome was made depending on the presence of clinical indications, elevated pressure or both. The study found that those patients who had pressure monitoring had earlier fasciotomy and fewer complications than those who had not.

The two groups are self-selected for two reasons:

1) It is possible (or even likely) that the monitored patients had the more obvious clinical features, and would have had early decompression with or without the insertion of a needle into their anterior tibial compartment. Some of these patients may have been better served by immediate fasciotomy rather than investigation.

2) The surgeons who decided to use pressure monitoring may have had a more active approach to the management of the acute compartment syndrome. There is no evidence to show that information gained from the invasive monitoring made any contribution to the clinical management or whether higher pressures were ever managed conservatively in the absence of clinical confirmation. The monitored group also achieved significantly more rapid union, possibly reflecting improved overall care.

In our (prospective) study of 150 closed or grade-I open tibial diaphyseal fractures treated by external fixation, three patients required early fasciotomy and in none of these was pressure monitoring used. In two others pressure monitoring confirmed the clinical impression that decompression was unnecessary. On careful review, no patient developed signs of a missed compartment syndrome.
We cannot accept that "when equipment is available, all patients with tibial fractures should have continuous compartment monitoring ....". Pressure monitoring of one or more compartments is a useful aid to clinical judgement, particularly in patients who are difficult to assess but it can be misleading and is not to be recommended in every case. Clinical vigilance is safer than universal monitoring.

\section{S. ROBERTS, FRCS}

P. THOMAS, FRCS

Royal Infirmary

Stoke-on-Trent, UK.

McQueen MM, Christie J, Court-Brown CM. Acute compartment syndrome in tibial diaphyseal fractures. $J$ Bone Joint Surg $[\mathrm{Br}]$ 1996;78-B:95-8.

\section{Author's reply:}

Sir,

The suggestion by Mr Roberts and Mr Thomas that the monitored patients in our series had more obvious clinical features implies that this group had more severe and aggressive compartment syndromes. Both groups had similar fractures and equivalent numbers of compartments decompressed, suggesting that the severity of injury was similar.

The usual reason for delay in making a diagnosis of acute compartment syndrome is a lack of appreciation of the possibility of the condition developing. Detection at an early stage may be dependent on the nursing staff who are in continuous contact with the patient. The use of compartment monitoring raises awareness among all staff of the possibility of the syndrome and it is in this that it has its greatest influence.

It is likely that the surgeons who decided to use pressure monitoring did have a more active approach to the management of acute compartment syndrome particularly since monitoring alone had a significant effect on the outcome. The pressure level alone was used to decide on decompression. Indeed, in the two patients in whom there was a clear association between reduction and fixation of the fracture and a rise to critical pressure levels, decompression was performed under the same anaesthetic.

All the fractures were actively treated by either intramedullary nailing or external fixation. In view of previous experimental work, quoted in the paper, we believe that the more rapid union is due to restoration of extraosseous and muscle blood flow after the fracture.

We do not agree that early continuous monitoring does not reduce the delay to fasciotomy. Clinical vigilance and compartment monitoring are not mutually exclusive.

M. M. MCQUEEN, MD, FRCS Ed(Orth)

Royal Infirmary of Edinburgh

Edinburgh, UK.

\section{PERCUTANEOUS AUTOGENOUS BONE-MARROW GRAFTING}

Sir,

I wish to comment on the brief report in the September 1995 issue by Garg and Gaur entitled 'Percutaneous autogenous bone-marrow grafting in congenital tibial pseudarthrosis' (1995; 77-B:8301). The authors presented the preoperative and postoperative AP and lateral radiographs of a 12-year-old boy with congenital pseudarthrosis of the right tibia. The preoperative film shows definite nonunion, despite an intramedullary fibular graft and 
cancellous bone graft.

After treatment by injection of bone-marrow aspirate into the pseudarthrosis, a plaster cast was applied and the injection repeated after three weeks. They claimed that by five months, there was successful clinical and radiological union.

The radiograph taken 18 months after operation showed no convincing evidence of union. A radiolucent line and sclerosis at the pseudarthrosis site were still present and there was no evidence of remodelling to form a proper medullary canal surrounded by cortices. Such a picture is often seen after free bone grafts, vascularised bone grafts at one or both ends and even after electrical stimulation. I would be extremely hesitant to call this a sound union. It would be most interesting to see what would happen to the bone on longer follow-up.

\section{J. C. Y. LEONG, FRCS, FRCS Ed, FRACS}

University of Hong Kong

Hong Kong.

Garg NK, Gaur S. Percutaneous autogenous bone-marrow grafting in congenital tibial pseudarthrosis. J Bone Joint Surg [Br] 1995; 77-B:830-1.

\section{Editor's reply:}

We thank Professor Leong for drawing our attention to Figure 1b in this brief report which purports to be a radiograph taken 18 months after operation. Unfortunately, during the process of publishing the article a radiograph taken five months after operation was wrongly chosen and labelled. We apologise for this, and now publish the correct radiographs taken 18 months after operation and showing sound union (Fig. 1).
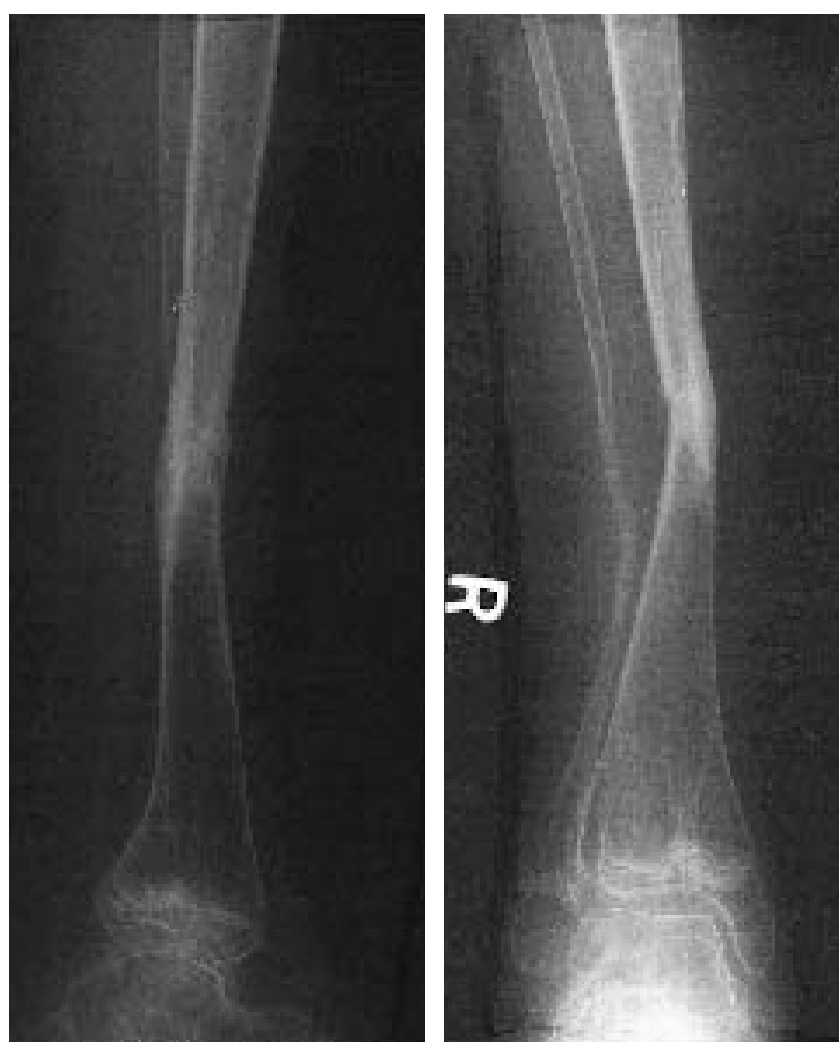

Fig. 1 